\title{
KONSEP PENDIDIKAN TAUHID MENURUT MUHAMMAD BIN 'ABDUL WAHHAB DAN RELEVANSINYA DENGAN KURIKULUM 2013
}

\author{
Redi Iskandar, Azis \\ Sekolah Tinggi Agama Islam Masjid Syuhada Yogyakarta \\ Email: Azisabdullah2018@gmail.com
}

\begin{abstract}
Abstrak
Penelitian ini bertujuan untuk mengkaji konsep pendidikan tauhid menurut Muhammad bin 'Abdul Wahhab dan relevansinya dengan pendidikan tauhid saat ini, khususnya dengan pendidikan tauhid di sekolah formal yang berlandaskan kurikulum 2013 tingkat Madrasah Tsanawiyah.

Jenis penelitian ini adalah library research, yakni yang mengkaji kepustakaan dari sebuah buku, transkrip, dan dokumen yang lainnya. Adapun pendekatan yang digunakan dalam penelitian ini adalah pendekatan sosiologis, yakni cara pandang atau paradigma yang melihat suatu gejala atau fenomena sebagai sesuatu yang tidak bisa lepas dari faktor sosial historis yang melingkupinya.

Hasil penelitian menunjukan bahwa, (1) dasar pendidikan tauhid Muhammad bin 'Abdul Wahhab adalah Al- Quran dan hadits, (2) materi pendidikan tauhid Muhammad bin 'Abdul Wahhab meliputi tauhid Rububiyah, tauhid uluhiyah, tauhid asma wa sifat, (3) tujuan pendidikan tauhid Muhammad bin 'Abdul Wahhab adalah untuk membimbing umat agar mengenal Allah Subhanahu Wa Ta'ala, memurnikan tauhid yang telah tercemar, melepaskan umat dari keterikatan terhadap thaghut, dan mencegah umat agar tidak terjerumus kedalam kesyirikan, dengan metode pendidikan tauhid meliputi metode tanya jawab, perumpamaan, kisah, dan tarhib wa targhib, (5) relevannya dengan pendidikan tauhid saat ini, khususnya dengan pendidikan tauhid di sekolah formal yang berlandaskan kurikulum 2013 tingkat Madrasah Tsanawiyah.
\end{abstract}

Kata kunci: Konsep, Pendidikan Religi, Kurikulum, formal 
This study aims to examine the concept of monotheistic education according to Muhammad bin 'Abdul Wahhab and its relevance to tauhid education today, especially with tauhid education in formal schools based on the 2013 curriculum at Madrasah Tsanawiyah.

This type of research is a library research, which is the one that examines the literature of a book, transcript, and other documents. The approach used in this study is a sociological approach, namely the perspective or paradigm that sees a phenomenon or phenomenon as something that cannot be separated from the historical social factors that surround it.

The results showed that, (1) the basis of the monotheistic education of Muhammad bin 'Abdul Wahhab was the Koran and hadith, (2) the monotheistic educational material Muhammad bin' Abdul Wahhab included tauhid Rububiyah, tauhid uluhiyah, tauhid asma wa traits, (3) purpose Muhammad bin 'Abdul Wahhab's tawhid education is to guide people to know Allah Subhanahu Wa Ta'ala, purify tauhid which has been polluted, release the ummah from attachment to taghout, and prevent the ummah from falling into kesyirikan, with the method of tauhid education including the question and answer method, parables, stories, and tarhib wa targhib, (5) relevance to tauhid education today, especially with tauhid education in formal schools based on the 2013 curriculum at the Madrasah Tsanawiyah level.

Keywords: Concepts, Religious Education, Curriculum, formal

\section{A. Latar Belakang Masalah}

Pendidikan yang dibutuhkan oleh setiap insan adalah pendidikan Islam yang berporos pada konsep pemurnian tauhid. Konsep pemurnian tauhid yang diterapkan dalam proses pendidikan akan memperkenalkan seorang hamba kepada Tuhan yang telah menciptakannya yaitu Allah Subhanahu Wa Ta'ala, sehingga dengan pengenalan tersebut akan mengarahkannya 
kepada puncak pengagungan, kecintaan, dan ketundukan terhadap-Nya.

Agama Islam adalah agama yang dibangun dengan berlandaskan asas ketauhidan. Konsep pemurnian tauhid dalam menjalankan pendidikan Islam adalah hal yang harus lebih diprioritaskan dari aspek-aspek yang lainnya. Hal ini sebagaimana yang telah diterapkan oleh semua Rasul ketika mereka berdakwah untuk mengajarkan agama Islam kepada umat manusia.

Setiap muslim dituntut untuk senantiasa memberikan perhatian terhadap kualitas tauhidnya. Tidak sepatutnya bagi seseorang yang mengaku muslim melalaikan dan meremehkan perkara tersebut. Hal itu dikarenakan kualitas tauhid seorang hamba sangat menentukan kebahagiaannya baik ketika hidup di dunia maupun di akhirat.

Konsentrasi sebagian umat Islam terhadap penanaman dan pemurnian tauhid semakin melemah, baik pada individu, keluarga, dan masyarakat secara umum. Di samping itu, kurangnya perhatian lembaga-lembaga pendidikan formal di tanah air dalam menanamkan aspek-aspek ketauhidan menjadi dilema tersendiri bagi umat Islam secara umum. Kurikulum pendidikan yang diterapkan oleh pemerintah lebih terfokus pada peningkatan aspek-aspek akademis dan kurang maksimal dalam menanamkan aspek-aspek keagamaan, sehingga banyak pelajar yang setatusnya muslim akan tetapi kurang memahami nilai-nilai 
keislaman, khususnya dalam aspek ketauhidan. Kondisi tersebut dapat mengancam eksistensi generasi Islam dimasa yang akan datang.

Kurangnya konsentrasi terhadap pemurnian tauhid dapat menyebabkan seorang muslim mudah kehilangan jati dirinya. Hal tersebut dikarenakan tidak adanya pemahaman yang benar terhadap makna tauhid itu sendiri, sehingga dengan mudah terjerumus kedalam perkara-perkara yang bertolak belakang dengan tauhid. Di antara perkara-perkara yang bertolak belakang dengan aspek-aspek ketauhidan adalah kesyirikan. Berbagai macam kesyirikan banyak tersebar diseluruh penjuru dunia. Begitu juga di Indonesia, banyak masyarakat yang belum memahami makna tauhid yang benar, sehingga mereka mudah terjebak dalam kesyirikan. Kesyirikan dengan berbagai bentuknya merupakan dosa yang paling besar di sisi Allah Subhanahu Wa Ta'ala, sehingga pelakunya terancam kekal di dalam Neraka. Hal tersebut dikarenakan telah menyekutukan Tuhan yang maha sempurna dengan makhluk yang sangat lemah.

Konsep pendidikan tauhid merupakan kebutuhan pokok yang harus diterapkan pada seluruh lapisan masyarakat, terlebih lagi di lembaga-lembaga pendidikan. Hal tersebut bertujuan untuk memperkuat keimanan, memperbaiki moral, dan memperbaiki tatanan masyarakat secara umum. Sebaliknya, jika konsep pendidikan tauhid tidak diterapkan, maka akan senantiasa terjadi kerusakan iman dan moral, sehingga hal 
tersebut dapat menyebabkan seseorang berada pada puncak kehinaan baik ketika hidup di dunia maupun di akhirat.

Konsep pendidikan tauhid merupakan inti dakwah Islam yang senantiasa dijunjung tinggi oleh para ulama. Di antara ulama yang menerapkan konsep ketauhidan dalam mendakwahkan dan mengajarkan Islam adalah Muhammad bin 'Abdul Wahhab. Konsep ketauhidan yang dirumuskannya mampu menarik perhatian umat Islam di zamannya ataupun di zaman setelahnya. Keproduktifannya dalam menghasilkan karya tulis menjadikannya sebagai sosok ulama yang menginspirasi umat Islam di dunia.

\section{B. Pembahasan}

\section{Pengertian Pendidikan Tauhid}

Albani berpendapat bahwa pendidikan adalah usaha untuk mengarahkan fitrah manusia dan segala karunia yang Allah Subhanahu Wa Ta'ala anugerahkan kepada mereka agar digunakan untuk beramal di muka bumi serta untuk menunaikan hak-hak-Nya atas dasar kekhilafahan. ${ }^{1}$ Adapun menurut Ki Hajar Dewantara pendidikan diartikan sebagai daya upaya untuk memajukan pertumbuhan nilai moral (kekuatan batin, karakter), pikiran (intelek), dan tumbuh anak yang antara satu dengan yang lainnya saling berhubungan

1 Ahmad Madkur, Manahij At-Tarbiyah, (Kairo: Darul Fikri Al-'Arobiy, 2001), hlm. 29. 
agar dapat memajukan kesempurnaan hidup dan penghidupan anak-anak yang kita didik selaras. ${ }^{2}$

Manusia dituntut untuk terus meningkatkan kualitas pendidikannya, terutama pada aspek sepiritualnya. Hal itu dikarenakan kualitas sepiritual merupakan tolak ukur yang sangat penting dalam membangun kehidupan yang lebih baik. Di antara upaya yang dibutuhkan untuk membangun sepiritual yang berkualitas adalah dengan menerapkan pendidikan tauhid.

Pendidikan tauhid adalah suatu upaya yang keras dan bersungguh-sungguh dalam mengembangkan, mengarahkan, membimbing akal, pikiran, jiwa, qalbu dan ruh kepada pengenalan dan cinta kepada Allah Subhanahu Wa Ta'ala. ${ }^{3}$ Pendidikan tauhid adalah landasan pertama yang harus dibangun pada diri seorang muslim yang dengannya semua kebaikan akan didapatkan. sebaliknya, tanpa pendidikan tauhid maka semua akan sia-sia. Kedudukan tauhid pada diri seorang muslim diibaratkan seperti pondasi bagi sebuah bangunan. Oleh karena itu, ketika tauhid seseorang lemah maka akan menimbulkan kehancuran bagi keislamannya sebagaimana robohnya bangunan dikarenakan lemahnya pondasi yang menjadi tumpuannya.

2 Ki Hajar Dewantara, Karya Ki Hajar Dewantara Bagian Pertama: Pendidikan, (Yogyakarta: Majelis Luhur Persatuan Taman Siswa, 2004), hlm. 14-25.

${ }^{3}$ M. Hamdani B. DZ, Pendidikan Ketuhanan Dalam Islam, (Surakarta: Muhammadiyah University Press, 2001), hlm. 10.

6 I AT-TUROTS: Jurnal Pendidikan Islam 
Ibnul Qoyyim menjelaskan bahwa siapa saja yang ingin meninggikan sebuah bangunan maka hendaknya dia mengokohkan, memantapkan, dan bersungguh-sungguh untuk memperhatikan kualitas pondasinya. Hal tersebut dikarenakan ketinggian bangunan sangatlah bergantung kepada kualitas pondasinya. Orang yang cerdas akan mengfokuskan perhatiannya pada perbaikan dan pengokohan pondasinya, sedangkan orang yang bodoh akan terfokus pada peninggian bangunannya serta mengabaikan pondasinya, sehinga bangunan yang telah ditinggikannya akan roboh. ${ }^{4}$

Tauhid adalah awal dan akhir dari seruan Islam. Ia adalah suatu kepercayaan kepada Tuhan Yang Maha Esa (faith in the unity of God). Suatu kepercayaan yang menegaskan bahwa hanya Tuhanlah yang menciptakan, memberi hukum-hukum, mengatur dan mendidik alam semesta ini (tauhid rububiyah). Sebagai konsekwensinya, maka hanya Tuhan itulah satusatunya yang wajib disembah, dimohon petunjuk dan pertolongan, serta yang harus diikuti (tauhid uluhiyah). Tuhan itu Zat yang luhur dari segala-galanya, hakim yang maha tinggi, yang tiada terbatas, yang kekal, yang tiada berubahubah, yang tiada kesamaannya sedikitpun di alam semesta ini,

4`Abdul Malik bin Ahmad bin Al-Mubarok Ramadhani Al-Hazairi, Sittu Duror Min Ushuli Ahli Atsar, (Kairo: Darul Imam Ahmad, 2007), hlm. 13. 
sumber segala kebaikan dan kebenaran, yang maha adil dan suci. Tuhan itu bernama Allah Subhanahu Wa Ta'ala. ${ }^{5}$

Berdasarkan penelitian terhadap Al-Quran dan haditshadits Nabi Shalallahu'Alahi Wa Sallam dapat diketahui bahwa tauhid terbagi menjadi tiga macam, yaitu tauhid rububiyah, tauhid uluhiyah, dan tauhid asma' wa sifat. Pembagian ini merupakan hasil penelitian mendalam yang dilakukan oleh para ulama terdahulu seperti Ibnu Mundih, Ibnu Jarir AtThabari, dan ulama yang lainnya. Pembagian ini juga disepakati oleh Ibnu Taimiyah dan muridnya yaitu Ibnul Qoyyim. ${ }^{6}$ Berikut ini adalah penjelasan dari masing-masing pembagian tersebut:

a. Tauhid Rububiyah

Tauhid rububiyah adalah keyakinan kuat yang disertai pengakuan bahwa Allah Subhanahu Wa Ta'ala adalah satusatunya Tuhan yang menciptakan dan menguasai alam semesta, memberikan rizki, menghidupkan, mematikan, memberikan manfaat, mendatangkan bencana, mengabulkan do'a ketika dalam kesusahan, milik-Nya segala kekuasaan, semua kebaikan ada di tangan-Nya, semua urusan kembali kepada-Nya, dan tidak ada satupun sekutu bagi-Nya. $^{7}$

${ }^{5}$ Nasrudin Razak, Dienul Islam, (Bandung: Alma'arif, 1989), hlm. 39.

'Bakar bin 'Abdillah Abu Zaid, At-Tahdzir Min Mukhtasharat Muhammad 'Ali AsShabuni Fi Tafsir, (Riyad: Darul Ibnul Jauzi, 1410 H), hlm. 30.

7 Abdul Qodir bin Muhammad 'Ath-Thashufi, op. cit., hlm. 56 
Shalih bin Fauzan bin 'Abdullah Al-Fauzan menjelaskan bahwa tauhid rububiyah sudah tertanam pada fitrah manusia. Ayat-ayat Al-Quran yang berkaitan dengan hal ini sangat banyak. Allah Subhanahu Wa Ta'ala menyebutkan bahwa orang-orang musyrik mengakui rububiyah-Nya. Tidak ada yang mengingkari dan menetang rububiyah Allah Subhanahu Wa Ta'ala kecuali sekelompok orang yang menyimpang dari fitrahnya. Mereka mengingkari dan menentang rububiyah-Nya hanya atas dasar kesombongan, sedangkan lubuk hati mereka meyakini bahwasannya Dia adalah satu-satunya Tuhan yang esa dalam rububiyah-Nya. ${ }^{8}$

b. Tauhid Uluhiyah

Muhammad bin Shalih Al-Utsaimin menjelaskan bahwa yang dimaksud tauhid uluhiyah adalah mengesakan Allah Subhanahu Wa Ta'ala dalam peribadatan. ${ }^{9}$ Inti dari tauhid ini adalah penghambaan dan peribadatan seorang hamba yang mutlak diserahkan hanya kepada Allah Subhanahu Wa Ta'ala. Oleh karna itu, siapa saja yang menghambakan diri dan menyerahkan ibadah kepada selain-Nya maka dia telah melakukan penyimpangan dalam tauhid uluhiyah.

8Shalih bin Fauzan bin 'Abdullah Al-Fauzan, op. cit., hlm. 27-28

${ }^{9}$ Muhammad bin Shalih Al-Utsaimin,op. cit., hlm. 11 
Tauhid uluhiyah memiliki keterkaitan dengan tauhid rububiyah. Shalih bin Fauzan bin 'Abdullah Al-Fauzan menjelaskan bahwa seseorang yang mentauhidkan Allah Subhanahu Wa Ta'ala dalam rububiyah-Nya, maka wajib baginya untuk mentauhidkan-Nya dalam uluhiyah-Nya. ${ }^{10}$ Oleh karena itu, jika seseorang mengakui bahwa Allah Subhanahu Wa Ta'ala adalah satu-satunya pencipta alam semesta, maka wajib baginya untuk menghambakan diri dan menyerahkan ibadah hanya kepada-Nya.

c. Tauhid Asma' Wa Sifat

Tauhid asma' wa sifat adalah mengesakan Allah Subhanahu $W a T a^{\prime} a l a$ dalam nama-nama dan sifat-sifat yang telah ditetapkan bagi-Nya, baik yang terdapat di dalam AlQuran ataupun yang terdapat di dalam hadits-hadits Nabi Shalallahu 'Alaihi Wasallam. Hal tersebut dilakukan dengan cara menetapkan semua nama dan sifat yang Allah Subhanahu Wa Ta'ala tetapkan untuk diri-Nya serta meniadakan semua nama dan sifat yang Allah Subhanahu Wa Ta'ala tiadakan dari-Nya dengan tanpa menyimpangkan maknanya, menolaknya, dan tanpa menyamakannya dengan makhluk-Nya. ${ }^{11}$

'Abdul 'Aziz Nashir Al-Jalil mengungkapkan bahwa ilmu yang paling bermanfaat dan yang paling mulia

\footnotetext{
10Shalih bin Fauzan bin 'Abdullah Al-Fauzan, op. cit., hlm. 35

${ }_{11}$ Muhammad bin Shalih Al-Utsaimin, Syarah Tsalatsatul Ushul, (Riyad: Daru AtsTsariyya, 2000), hlm. 40.
} 
kedudukannya adalah ilmu tentang nama dan sifat Allah Subhanahu Wa Ta'ala. Hal tersebut dikarenakan ketika seseorang mempelajari nama-nama dan sifat-sifat Allah Subhanahu Wa Ta'ala maka dia akan semakin mengenal-Nya, sehingga hal tersebut akan mendorongnya untuk beribadah kepada-Nya, mencintai-Nya, takut kepada-nya, mengagungkan-Nya, dan memuliakan-Nya. ${ }^{12}$

Tiga pengelompokan tauhid di atas dirumuskan oleh para ulama agar memudahkan umat Islam dalam memahaminya, sehingga tidak terjadi kesalahan ketika merealisasikannya. Seorang hamba dikatakan bertauhid jika telah merealisasikan tiga macam tauhid tersebut dalam kehidupannya. Adapun jika seorang hamba hanya merealisasikan sebagiannya saja maka tidak bisa dikatakan sebagai orang yang telah mentauhidkan Allah Subhanahu Wa Ta'ala. Artinya, seseorang yang tidak merealisasikan ketiga macam tauhid tersebut maka dia telah keluar dari Islam.

Proses pendidikan dalam kegiatan pembelajaran atau dalam kelas, akan bisa berjalan dengan lancar, kondusif, interaktif, dan lain sebagainya apabila dilandasi oleh dasar kurikulum yang baik dan benar. Pendidikan bisa dijalankan dengan baik ketika kurikulum menjadi penyangga utama dalam proses belajar mengajar. Kurikulum mengandung sekian

12 'Abdul 'Aziz Nashir Al-Jalil, Mukhtashar Kitab Wa Lillahi Asmaulhusna, (Riyad: Maktabah Al-Mulk Fahd Al-Wathaniyah Atsna An-Nasyr, 1436 H), hlm. 7. 
banyak unsur konstruktif supaya pembelajaran terlaksana secara optimal. Sejumlah pakar kurikulum berpendapat bahwa jantung pendidikan berada pada kurikulum. ${ }^{13}$

A. Ferry T. Indratno mengatakan bahwa kurikulum adalah program dan isi dari suatu sistem pendidikan yang berupaya melaksanakan proses akumulasi pengetahuan antar generasi dalam masyarakat. Bila ditarik benang merah maka kurikulum dapat dipahami sebagai alat sentral bagi keberhasilan pendidikan. Peran ini menjadi kunci bagaimana pendidikan akan diarahkan. Ini berkaitan erat dengan proses pembelajaran sebagai ruang beraktivitas belajar anak didik supaya mereka mendapat bekal pengetahuan yang baik dan mampu membangun kekuatan kecerdasan baik kognitif, afektif, dan psikomotorik. ${ }^{14}$

Di antara contoh kurikulum yang di terapkan oleh pemerintah tanah air adalah Kurikulum 2013 (K13). Kurikulum 2013 (K13) adalah langkah lanjutan pengembangan Kurikulum Berbasis Kompetensi yang telah dirintis pada tahun 2004 dan KTSP 2006 yang mencakup kompetensi sikap, pengetahuan dan keterampilan secara terpadu.

\section{Metode Penelitian}

\footnotetext{
${ }_{13}$ Moh. Yamin, Panduan Manajemen Mutu Kurikulum Pendidikan, (Yogyakarta: DIVA Press, 2012), hlm. 13.

14 Ibid., hlm. 15
} 
Jenis penelitian ini adalah kajian pustaka (library research) yang merupakan bagian dari penelitian kualitatif, yakni yang mengkaji kepustakaan dari sebuah buku. Sumber tidak hanya terbatas pada buku, namun bisa juga transkrip atau dokumen yang lain. Misalnya bukti rekaman, wawancara dengan penulis secara langsung dan yang lainnya. Istilah lain yang digunakan untuk kajian pustaka adalah Studi Literatur atau Literature Research. ${ }^{15}$

Pendekatan yang digunakan dalam penelitian ini adalah pendekatan sosiologis, yakni cara pandang atau paradigma yang melihat suatu gejala atau fenomena sebagai sesuatu yang tidak bisa lepas dari faktor sosial historis yang melingkupinya. ${ }^{16}$

Pendekatan sosiologis digunakan untuk menjaring data yang berhubungan dengan situasi yang melatarbelakangi konsep pendidikan tauhid menurut Muhammad bin 'Abdul Wahhab. Pendekatan ini digunakan mengingat materi penelitian ini berkaitan dengan pemikiran seorang tokoh melalui karyakaryanya di masa lalu dengan melihat situasi dan kondisi historis yang melatarbelakangi kehidupannya.

${ }^{15}$ Tim Penyusun Pedoman Penulisan Skripsi Program Sarjana (strata-1) STAIM Masjid Syuhada, Pedoman Penulisan Skripsi, (Yogyakarta: STAIMS Press, 2018), hlm. 25.

16Ibid., 
Data primer merupakan data utama yang digunakan sebagai objek penelitian. ${ }^{17}$ Adapun sumber data primer dalam penelitian ini adalah:

1. Kitab berbahasa arab dengan judul "Silsilah Syarah Ar-Rasail" karya Shalih bin Fauzan bin 'Abdullah Al-Fauzan. Kitab "Silsilah Syarah Ar-Rasail" diterbitkan oleh Pustaka Darul Ma'tsur pada tahun 2015 di Mesir. Kitab tersebut memuat pernyataan dan pemikiran Muhammad bin 'Abdul Wahhab yang dilengkapi dengan penjelasan Shalih bin Fauzan bin 'Abdullah Al-Fauzan. Jumlah halaman di dalam kitab tersebut adalah 237 halaman dengan sampul berwarna hitam yang bertuliskan tinta emas.

2. Kitab berbahasa arab dengan judul "Mutun Thalibil 'Ilmi Mustawa Awwal" karya "Abdul Muhsin bin Muhammad AlQasim. Kitab "Mutun Thalibil 'Ilmi Mustawa Awwal" diterbitkan oleh Pustaka Al-Mulk Fahd Al-Wathaniyah Atsna An-Nassyr pada tahun $1435 \mathrm{H}$ di Riyad. Kitab tersebut memuat pernyataan dan pemikiran Muhammad bin 'Abdul Wahhab dengan tanpa diberikan penjelasan oleh 'Abdul Muhsin bin Muhammad Al-Qasim. Jumlah halaman di dalam kitab tersebut adalah 136 halaman dengan sampul berwarna kuning.

\section{Hasil Penelitian}

17 Ibid.,hlm. 20

14 | AT-TUROTS: Jurnal Pendidikan Islam 
Konsep pendidikan Tauhid menurut Muhammad bin 'Abdul Wahhab sebagai berikut:

1. Dasar Pemikiran Muhammad bin 'Abdul Wahhab

Muhammad bin Abdul Wahhab adalah seorang ulama yang sangat menjunjung tinggi nilai-nilai yang terkandung di dalam Al-Quran dan As-Sunnah. Kedua sumber hukum Islam tersebut senantiasa menjadi landasan utamanya dalam merumuskan konsep keislaman, khususnya dalam ranah pendidikan tauhid. Shalih bin Fauzan bin 'Abdullah AlFauzan, ketika mengomentari salah satu kitab karangan Muhammad bin 'Abdul Wahhab yang berjudul "Al-Qowa'id Al-Arba" menyatakan bahawa kaidah-kaidah yang dirumuskan oleh Muhammad bin 'Abdul Wahhab di dalam kitabnya tersebut bukan berdasarkan hasil pemikirannya sendiri sebagaimana yang dilakukan oleh sebagian orang, akan tetapi kaidah-kaidah tersebut dibuat berdasarkan hasil penelitiannya terhadap Al-Quran dan hadtis-hadits Nabi Shallallahu 'Alaihi Wa Sallam yang kemudian dirumuskan menjadi sebuah kesimpulan. ${ }^{18}$ Pernyataan tersebut diperkuat oleh ungkapanungkapan yang dikemukakan oleh Muhammad bin 'Abdul Wahhab sendiri ketika menjelaskan konsep pemikirannya, yang mana dia senantiasa menyertakan ayat-ayat Al-Quran dan hadits-hadits Nabi Shallallahu 'Alaihi Wa Sallam sebagai

18Shalih bin Fauzan bin 'Abdullah Al-Fauzan, Syarhu Al-Qowa'id Al-Arba', ( Mesir: Daru Sabilu Ar-Rassyad, 2017), hlm. 6. 
landasan dalam menetapkan sebuah kesimpulan hukum. Berikut ini adalah contoh pernyataan yang diungkapkan oleh Muhammad bin 'Abdul Wahhab:

a. Hukum Perbuatan Sihir

Sihir adalah salah satu perbuatan yang dimurkai oleh Allah Subhanahu Wa Ta'ala. Sihir merupakan perbuatan yang bertentangan dengan tauhid. Muhammad bin 'Abdul Wahhab menegaskan bahwa sihir adalah salah satu pembatal keislaman. Dia berkata:

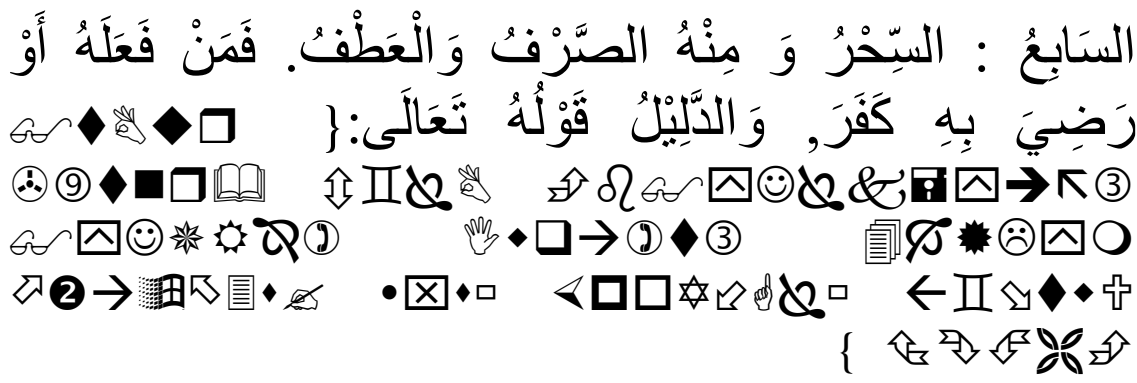

Artinya:

Pembatal keislaman yang ketujuh adalah perbuatan sihir. Contohnya adalah sihir athaf dan sharf. Siapa saja yang melakukannya atau menyetujuinya maka dia telah kafir. Dalilnya adalah firman Allah Subhanahu Wa Ta'ala yang artinya:“Padahal keduanya tidak mengajarkan sesuatupun kepada seseorang sebelum mengatakan "Sesungguhnya kami hanyalah cobaan bagimu, oleh karena itu janganlah kalian kafir". ( QS. Al-Baqarah: 102)19

Ayat yang disebutkan oleh Muhammad bin 'Abdul Wahhab di atas berkaitan dengan perbuatan sihir yang

${ }^{19}$ Abdul Muhsin bin Muhammad Al-Qasim, Mutun Thalibil 'Ilmi Mustawa Awwal, (Riyad: Maktabah Al-Mulk Fahd Al-Wathaniyah Atsna An-Nassyr, 1435 H) hlm. 27. 
dilakukan pada zaman Nabi Sulaiman 'Alaihissalam oleh kaumnya yang ingkar. Di antara jenis sihir yang berkembang pada saat itu adalah athaf dan sharf, yakni sihir yang bisa membuat rumah tangga seseorang bercerai berai dan membuat seseorang memiliki kecenderungan rasa cinta kepada orang lain.

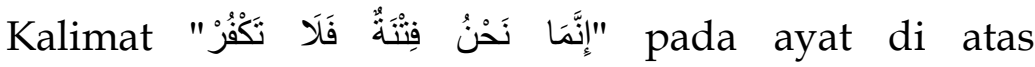
menunjukkan bahwa sihir adalah ujian bagi umat Nabi Sulaiman 'Alaihissalam yang harus dihindari oleh siapapun, termasuk oleh umat Nabi Muhammad Shallahu 'Alaihi Wa Sallam. Hal tersebut dikarenakan perbuatan sihir merupakan bentuk kekafiran yang akan membatalkan tauhid seseorang.

b. Hukum Menyembelih Hewan Untuk Selain Allah

Menyembelih hewan adalah salah satu ibadah yang sangat agung. Siapapun yang hendak menyembelih hewan maka harus diikhlaskan hanya kepada Allah Subhanahu Wa $\mathrm{Ta}^{\prime} a l a$. Barang siapa yang menyembelih hewan untuk selain Allah Subhanahu Wa Ta'ala, maka dia telah melakukan penyimpangan tauhid. Muhammad bin 'Abdul Wahhab berkata: Dalil tentang terlarangnya menyembelih hewan untuk selain Allah adalah firman Allah Subhanahu Wa Ta'ala yang artinya "Katakanlah sesungguhnya shalatku, sesembelihanku, hidupku, dan matiku hanya untuk Allah Tuhan semesta alam". ( QS. Al-An'am: 162). Adapun dalil dari hadits adalah sabda Nabi Shallalahu 'Alaihi Wa Sallam 
yang artinya "Allah Subhanahu Wa Ta'ala melaknat siapa saja yang menyembelih hewan untuk selain-Nya. (HR. Muslim) $)^{20}$

2. Materi Pendidikan Tauhid Muhammad bin 'Abdul Wahhab

Materi pendidikan tauhid terdiri dari tiga aspek, yaitu aspek rububiyah, uluhiyah, dan asma wa sifat. Muhammad bin 'Abdul Wahhab berkata: Di dalam surat Al-Fatihah terkandung makna uluhiyyah, rububiyah, dan peniadaan sifat-sifat buruk bagi Allah Subhanahu Wa Ta'ala ( asma'wa sifat). ${ }^{21}$. Adapun perinciannya adalah:

a. Aspek Rububiyah

Ruang lingkup aspek rububiyah meliputi keimanan terhadap keberadaan Tuhan (Allah), keesaan Allah Subhanahu Wa Ta'ala dalam menghidupkan dan mematikan makhluk, penciptaan dan kepemilikan alam semesta beserta pengaturannya, pemberian rizki, dan penetapan hukum syari'at. Pada poin ini Muhammad bin 'Abdul Wahhab mengungkapkan konsep pemikirannya kedalam tiga pembahasan pokok, yaitu: keberadaan Allah, penetapan hukum syari'at dan keyakinan kaum musyrikin Jahiliyah.

b. Aspek Uluhiyah

Ruang lingkup pembahasan aspek uluhiyah berfokus pada perbuatan-perbuatan hamba yang berorientasi pada makna penghambaan dan ketundukan kepada Allah

${ }^{20}$ Ibid., hlm. 54

21Shalih bin Fauzan bin 'Abdullah Al-Fauzan, Silsilah Syarh Ar-Rasail, ( Mesir: Darul Ma'tsur, 2015), hlm. 127. 
Subhanahu Wa Ta'ala. Totalitas penghambaan dan ketundukan terhadap hukum-hukum-Nya merupakan wujud nyata dari hakikat uluhiyah. Pada poin ini Muhammad bin 'Abdul Wahhab merumuskan konsep yang sangat luas. Hal tersebut dilatarbelakangi oleh kondisi umat Islam di zamannya khususnya di Jazirah Arab, yang mana pada saat itu terjadi banyak penyimpangan tauhid, khususnya dalam aspek uluhiyah. Di antara poin pokok dalam pembahasan ini adalah:

1) Hakikat Iman Kepada Allah

Iman memiliki cakupan pembahasan yang sangat luas. Di antara pokok keimanan yang pertama kali harus tertanam pada diri seseorang adalah iman kepada Allah Subhanahu Wa Ta'ala. Muhammad bin 'Abdul Wahhab mendefinisikan iman kepada Allah Subhanahu Wa Ta'ala dengan makna yang sangat sepesifik, yang mana dia mengatakan:
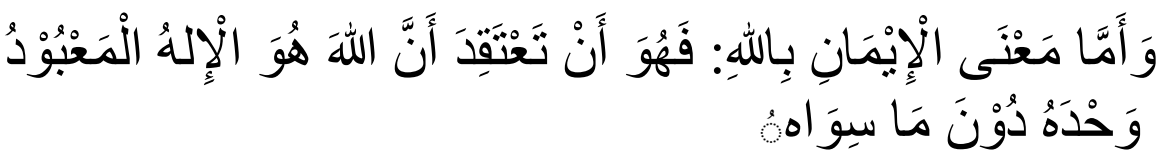

Artinya:

Adapun makna iman kepada Allah adalah meyakini bahwa Allah Subhanahu Wa Ta'ala adalah satu-satunya Tuhan yang berhak untuk disembah. ${ }^{22}$

22Shalih bin Fauzan bin 'Abdullah Al-Fauzan, op. cit., hlm. 186 
Pernyataan di atas menunjukkan bahwa hakikat iman kepada Allah Subhanahu Wa Ta'ala adalah berorientasi pada makna uluhiyah, yakni menyerahkan ibadah hanya untuk Allah Subhanahu Wa Ta'ala semata. Tidak cukup hanya dengan pengakuan hati dan lisan, seseorang yang mengaku beriman kepada Allah Subhanahu Wa Ta'ala harus merealisasikannya kedalam bentuk peribadatan yang diserahkan hanya kepada Allah Subhanahu Wa Ta'ala semata. Siapa saja yang mengaku beriman kepada Allah Subhanahu Wa Ta'ala, akan tetapi masih menyekutukan-Nya dalam peribadatan, maka pengakuanya dianggap sebagai sebuah kedustaan.

2) Hakikat Ibadah

Ibadah adalah semua perkataan dan perbuatan yang dicintai oleh Allah Subhanahu Wa Ta'ala, baik yang bersifat dhahir ataupun batin. Ibadah merupakan perkara yang harus direalisasikan oleh setiap orang agar bisa mewujudkan tauhid uluhiyah. Ibadah memiliki bentuk yang beraneka ragam, akan tetapi memiliki konsep yang sama dalam pelaksanaannya. Muhammad bin 'Abdul Wahhab berkata: Di antara contoh ibadah yang diperintahkan oleh Allah Subhanahu Wa Ta'ala adalah Islam (rukun Islam), iman, ihsan, do'a, rasa takut, rasa harap, tawakkal, rasa cinta, rasa cemas, khusyu', 
rasa khawatir, taubat, memohon pertolongan, memohon perlindungan, memohon bantuan ketika dalam kesusahan, menyembelih hewan, nadzar, dan yang lainnya, semua bentuk ibadah tersebut harus diserahkan kepada Allah Subhanahu Wa Ta'ala semata. ${ }^{23}$

Pernyataan yang diungkapkan oleh Muhammad bin 'Abdul Wahhab di atas mengandung dua konsep penting, yaitu: pertama, ibadah tidak terbatas pada amalan anggota badan, akan tetapi mencakup hati dan lisan. Kedua, semua bentuk ibadah harus diserahkan kepada Allah Subhanahu Wa Ta'ala semata. Sebuah kekeliruan jika ada yang beranggapan bahwa ibadah hanya terbatas pada ibadah dhahir saja, seperti shalat, haji, puasa dan yang lainnya.

3) Kalimat Tauhid (لَالَإِلََ إِلَّا اللهُ (Kon)

Kalimat tauhid merupakan kalimat yang memiliki kedudukan yang tinggi di sisi Allah Subhanahu Wa Ta'ala. Kalimat tersebut mengandung makna uluhiyah yang harus dipahami oleh setiap insan. Muhammad bin 'Abdul Wahhab berkata: Kalimat tauhid merupakan kalimat yang menjadi titik pembeda antara kekufuran dan Islam. Kalimat tersebut adalah kalimat takwa yang telah direalisasikan oleh Nabi Ibrahim 'Alaihi Wasallam dan keturunannya. Untuk merealisasikan kalimat

${ }^{23}$ Abdul Muhsin bin Muhammad Al-Qasimi, op. cit., hlm. 51-52 
tersebut tidak cukup hanya dengan ucapan saja, karena orang munafik juga mengucapakannya, akan tetapi mereka tetap divonis kafir. ${ }^{24}$

Pernyataan di atas menunjukkan bahwa menurut Muhammad bin 'Abdul Wahhab, kalimat tauhid memiliki tuntutan yang harus dipenuhi oleh siapa saja yang telah mengucapkannya. Orang-orang munafik mengucapkan kalimat tersebut, akan tetapi mereka tidak dikatakan bertauhid. Hal tersebut dikarenakan mereka tidak memenuhi syarat-syaratnya. Di antara syaratsyarat yang harus dipenuhi ketika seseorang sudah mengucapkan kalimat tersebut adalah: petama, memahami makna yang terkandung di dalamnya, yakni memahami bahwa hanya Allah Subhanahu Wa Ta'ala yang berhak untuk disembah. Kedua, yakin dan tidak boleh ragu sedikitpun terhadap makna yang terkandung di dalamnya. Ketiga, menerima tuntutan yang terkandung di dalamnya, baik dengan hati ataupun lisan. Keempat, tunduk terhadap tuntutan yang terkandung di dalamnya, yakni dengan melaksanakan ibadah dan menyerahkanya hanya untuk Allah Subhanahu Wa Ta'ala. Kelima, jujur ketika mengucapkannya. Keenam, ikhlas ketika mengucapkannya dan tidak melakukan kesyirikan.

24 Shalih bin Fauzan bin 'Abdullah Al-Fauzan, op. cit., hlm. 81

22 AT-TUROTS: Jurnal Pendidikan Islam 
Ketujuh, mencintai kalimat tersebut, mencintai orang yang merealisasikannya, dan membenci semua hal yang bertentangan dengannya.

Kalimat tauhid mengandung dua rukun yang tidak dapat dipisahkan, yaitu meniadakan semua sesembahan ( الإلَة ) dan menetapkan Allah Subhanahu Wa Ta'ala sebagai satu-satunya sesembahan ( إلَّا l) Seseorang yang sudah mengucapkan kalimat tauhid maka dia harus menolak semua sesembahan dan hanya menetapkan Allah Subhanahu Wa Ta'ala sebagai satusatunya sesembahan di alam semesta ini.

4) Hakikat Agama Nabi Ibrahim 'Alaihissallam

Nabi Ibrahim 'Alaihissallam adalah suri tauladan bagi orang-orang yang bertauhid. Ketundukannya terhadap nilai-nilai tauhid menjadikannya sebagai manusia yang memiliki kedudukan tinggi di sisi Allah Subhanahu Wa Ta'ala. Pada poin ini Muhammad bin 'Abdul Wahhab menjelaskan tentang hakikat agama Nabi Ibrahim 'Alaihissallam. Muhammad bin 'Abdul Wahhab berkata: Bahwa agama Nabi Ibrahim 'Alaihi Wasallam adalah Al-Hanifiyah, yaitu mengikhlaskan ibadah hanya kepada Allah Subhanahu Wa Ta'ala. Ini adalah perkara yang diperintahkan kepada seluruh manusia dan sekaligus sebagai tujuan penciptaan mereka. Sebagaimana firman Allah Subhanahu Wa Ta'ala 
yang artinya:"Dan aku tidak menciptakan jin dan manusia melainkan supaya mereka beribadah kepadaKu". ( QS: Adz-Dzariyat: 56 ). Dan yang dimaksud ibadah adalah mentauhidkan Allah Subhanahu Wa Ta'ala. $^{25}$

5) Hakikat Syirik

Pengertian syirik secara bahasa adalah "menyertakan sesuatu". Adapun pengertian syirik secara istilah adalah menjadikan makhluk sebagai tandingan bagi Allah Subhanahu Wa Ta'ala dalam hakhak yang menjadi kekhususan bagi-Nya, baik dalam aspek rububiyah, uluhiyah, dan asma' wa sifat-Nya. ${ }^{26}$ Syirik merupakan perbuatan yang paling dibenci oleh Allah Subhanahu Wa Ta'ala yang harus dihindari oleh siapapun. Muhammad bin 'Abdul Wahhab menjelaskan tentang hakikat kesyirikan dengan perkataannya: Sesungguhnya Allah Subhanahu Wa Ta'ala tidak ridha disekutukan dengan apapun dalam peribadatan, baik itu dengan Malaikat ataupun Nabi. Dalilnya adalah firman Allah Subhanahu Wa Ta'ala yang artinya: "Dan sesungguhnya masjid-masjid itu adalah kepunyaan

\footnotetext{
${ }^{25}$ Abdul Muhsin bin Muhammad Al-Qasimi, op. cit., hlm. 47

${ }^{26}$ Abdullah bin 'Adul 'Aziz Al-Jibrin, op. cit., hlm. 69-70
}

24 | AT-TUROTS: Jurnal Pendidikan Islam 
Allah. Maka janganlah kamu menyembah seorangpun di dalamnya di samping (menyembah) Allah".( QS. Al-Jin: $18)^{27}$

6) Hakikat Thaghut

Thaghut adalah segala sesuatu yang disembah selain Allah Subhanahu Wa Ta'ala. Pembahasan tentang hakikat thaghut merupakan pembahasan yang sangat penting dalam Islam. Hal tersebut dikarenakan thaghut adalah ancaman utama yang akan menjerumuskan manusia kedalam penyimpangan tauhid, bahkan inti dakwah para rasul adalah membebaskan manusia dari penghambaan diri kepada thaghut. Hal ini berdasarkan firman Allah Subhanahu Wa Ta'ala:

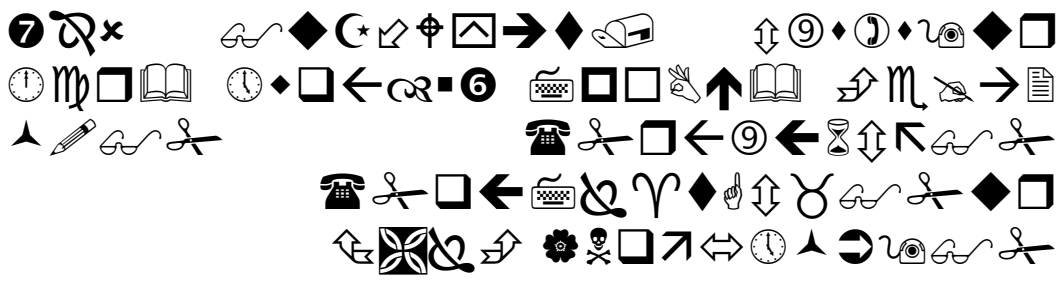

Artinya:

Dan sungguhnya Kami telah mengutus Rasul pada tiaptiap umat (untuk menyerukan): "Sembahlah Allah (saja), dan jauhilah thaghut itu". ( QS. An-Nahl: 36)

Berdasarkan hal ini Muhammad bin 'Abdul Wahhab menegaskan dengan perkataannya: Allah Subhanahu Wa Ta'ala mewajibkan kepada semua hamba

${ }^{27}$ Abdul Muhsin bin Muhammad Al-Qasimi, op. cit., hlm. 45 
agar mengingkari thaghut dan beriman kepada-Nya. Ibnul Qayyim berkata bahwa makna thaghut adalah segala sesuatu yang melampaui batas dari seorang hamba, baik dalam hal disembah, diikuti, dan ditaati. Thaghut memiliki jenis yang beraneka ragam, akan tetapi yang menjadi pokoknya terdiri dari lima macam, yaitu Iblis, orang yang disembah dan rela untuk disembah, orang yang memerintahkan orang lain untuk menyembahnya, orang yang mengaku mengetahui perkara ghaib, dan orang yang menetapkan hukum yang tidak bersumber dari hukum Allah Subhanahu Wa Ta'ala. $^{28}$

7) Prinsip Al-Wala' Wa Al-Bara'

Prinsip al-wala' wa al-bara' merupakan bagian dari tuntutan tauhid yang merupakan pokok keimanan. Prinsip tersebut harus direalisasikan oleh sipapun yang beriman kepada Allah Subhanahu Wa Ta'ala. Al-wala' wa al-bara' adalah mencintai orang-orang yang bertauhid (al-wala') dan membenci orang-orang yang menjadi musuh mereka (al-bara'). Muhammad bin 'Abdul Wahhab menegaskan dengan perkataannya: Siapa saja yang taat kepada Rasul dan mentauhidkan Allah Subhanahu Wa Ta'ala maka tidak boleh baginya berkasih sayang dengan orang yang memusuhi Allah Subhanahu

${ }^{28}$ Abdul Muhsin bin Muhammad Al-Qasimi, op. cit., hlm. 73-74 
Wa Ta'ala dan Rasul-Nya, meskipun mereka adalah kerabat dekatnya. Dalilnya adalah firman Allah Subhanahu Wa Ta'ala yang artinya: “Kamu tak akan mendapati kaum yang beriman pada Allah dan hari akhirat, saling berkasih-sayang dengan orang-orang yang menentang Allah dan Rasul-Nya, sekalipun orangorang itu bapak-bapak, atau anak-anak atau saudarasaudara ataupun keluarga mereka. Mereka itulah orangorang yang telah menanamkan keimanan dalam hati mereka dan menguatkan mereka dengan pertolongan yang datang daripada-Nya. Dan dimasukan-Nya mereka ke dalam surga yang mengalir di bawahnya sungai-sungai, mereka kekal di dalamnya. Allah ridha terhadap mereka, dan merekapun merasa puas terhadap (limpahan rahmat)-Nya. Mereka itulah golongan Allah. Ketahuilah, bahwa sesungguhnya hizbullah itu adalah golongan yang beruntung". (QS. Al-Mujadilah: 22)29

c. Aspek Asma' Wa Sifat

Konsep pemikirannya yang berkaitan dengan aspek asma' wa sifat hanya terbatas pada pernyataan umum saja. Hal ini berdasarkan perkataannya: Aku meyakini bahwa tidak ada yang semisal dengan Allah Subhanahu Wa Ta'ala, Dia maha mendengar lagi maha melihat. Aku tidak meniadakan sifat-sifat-Nya, tidak menyimpangkan

${ }^{29}$ Abdul Muhsin bin Muhammad Al-Qasimi, op. cit., hlm. 46 
maknanya, tidak menyimpangkan dan mengigkari nama dan ayat-ayat-Nya, tidak membayangkan bentuk fisik-Nya, dan tidak menyamakan-Nya dengan makhluk. ${ }^{30}$

Pernyataan di atas adalah kaidah umum yang merupakan materi pendidikan tauhid Muhammad bin 'Abdul Wahhab, khususnya dalam hal yang berkaitan dengan tauhid asma' wa sifat. Inti dari kaidah di atas adalah menegaskan tentang agungnya nama dan sifat Allah Subhanahu Wa Ta'ala, sehingga tidak selayaknya untuk disejajarkan dengan makhluk-makhluk-Nya. Hal ini selaras dengan firman Allah Subhanahu Wa Ta'ala:

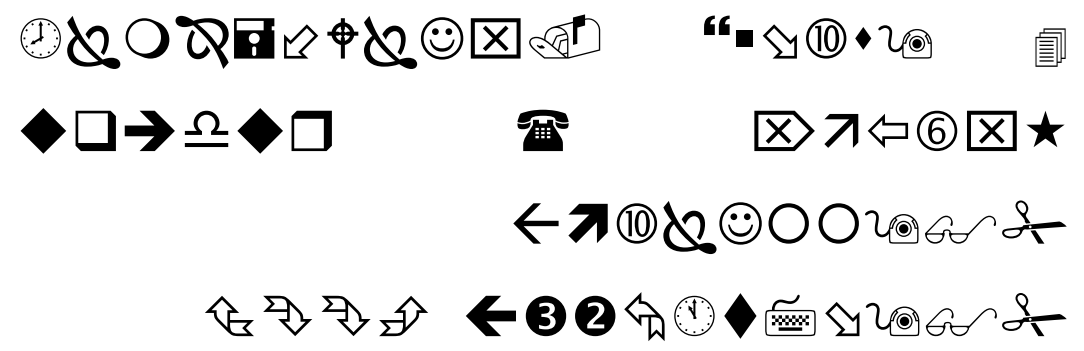

Artinya:

Tidak ada sesuatupun yang serupa dengan Dia, dan Dia-lah yang Maha mendengar dan melihat. (QS. As-Syura: 11)

3. Tujuan Pendidikan Tauhid Muhammad bin 'Abdul Wahhab

Nurlaelah Abbas menegaskan bahwa tujuan utama ajaran Muhammad bin 'Abdul Wahhab adalah memurnikan tauhid umat yang sudah tercemar. Untuk itu, dia sangat serius dalam memberantas bid'ah, khurafat, dan takhayul yang berkembang di

30 'Abdul Mun'im Ibrahim, op. cit., hlm. 44 
tengah-tengah umat. Dia menentang pemujaan terhadap orang-orang suci, mengunjungi tempat-tempat keramat untuk mencari berkah. Muhammad bin 'Abdul Wahhab menganggap bahwa segala macam objek pemujaan selain kepada Allah Subhanahu Wa Ta'ala adalah palsu dan merupakan bentuk kesyirikan. ${ }^{31}$

Kajiannya melalui berbagai metode dalam menyampaikan materi pendidikan tauhid yang telah dirumuskannya, yaitu:

a. Metode Tanya Jawab

Muhammad bin 'Abdul Wahhab berkata: Jika anda ditanya :" siapa tuhan anda"? , maka jawabalah:" Tuhanku adalah Allah Subhanahu Wa Ta'ala yang telah memeliharaku dan memelihara alam semesta ini, Dia adalah sesembahanku, dan tidak ada yang aku sembah selain Dia. ${ }^{32}$

Ungkapan di atas merupakan salah satu contoh metode pendidikan tauhid yang diterapkan oleh Muhammad bin 'Abdul Wahhab. Inti dari pernyataan di atas adalah usaha Muhammad bin 'Abdul Wahhab untuk membimbing objek dakwahnya agar mengenal Tuhannya yaitu Allah Subhanahu Wa Ta'ala. Muhammad bin 'Abdul Wahhab mengemasnya

31 Nurlaelah Abbas, Dakwah Tablig: " Muhammad bin 'Abdul Wahhab: Gerakan Revivalisme dan Pengaruhnya”. (UIN Alauddin Makasar. 2015. Volume 16, Nomor 2). hlm 141 .

${ }^{32}$ Abdul Muhsin bin Muhammad Al-Qasimi, op. cit., hlm. 49 
kedalam bentuk tanya jawab agar objek dakwahnya lebih perhatian terhadap materi yang akan disampaikannya, sehingga memudahkan objek dakwahnya dalam memahaminya. Metode ini juga banyak dilakukan oleh sebagian pendidik ketika menjalankan proses pembelajaran.

b. Metode Perumpamaan

Muhammad bin 'Abdul Wahhab berkata: Ketahuilah ! bahwa ibadah itu tidak akan sah jika tidak disertai dengan tauhid, sebagaimana shalat tidak akan sah jika tidak diawali dengan bersuci. ${ }^{33}$

Pernyataan di atas menunjukkan bahwa Muhammad bin 'Abdul Wahhab menggunakan metode perumpamaan dalam melaksanakan proses pendidikan tauhid. Hal tersebut bisa diketahui dari ungkapannya yang menyatakan bahwa kedudukan tauhid dalam ibadah semisal dengan kedudukan thaharah dalam shalat. Ibadah tidak akan diterima jika tidak disertai dengan tauhid sebagaimana shalat tidak akan sah jika tidak disertai bersuci. Metode ini diterapkan agar memudahkan objek dakwahnya dalam merespon materi yang disampaikannya. Metode perumpamaan juga terdapat di dalam Al-Quran, di antaranya firman Allah Subhanahu Wa Ta'ala:

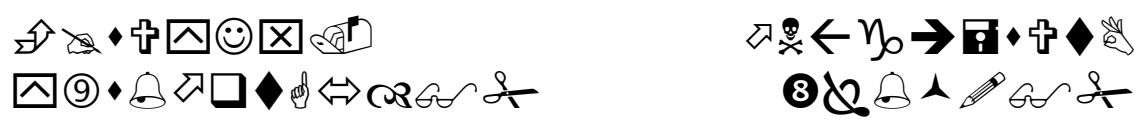

${ }^{33}$ Abdul Muhsin bin Muhammad Al-Qasimi, op. cit., hlm. 32 


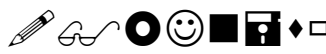

$8 \otimes 6$

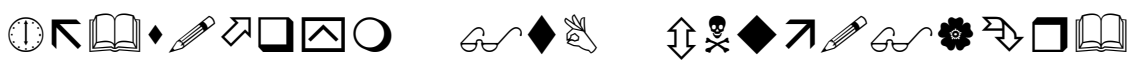

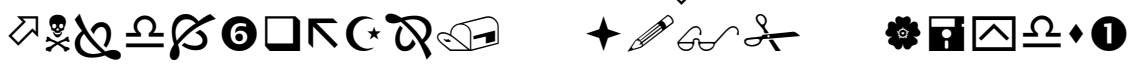

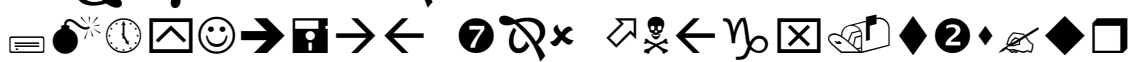

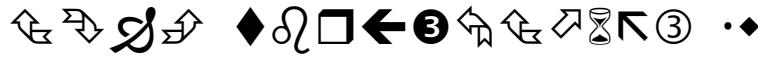

Artinya:

Perumpamaan mereka seperti orang yang menyalakan api, setelah menerangi sekelilingnya, Allah melenyapkan cahaya (yang menyinari) mereka dan membiarkan mereka dalam kegelapan, tidak dapat melihat.(QS. Al-Baqarah: 17) ${ }^{34}$

c. Metode Kisah

Muhammad bin 'Abdul Wahhab berkata: Nabi Shallallahu 'Alaihi Wasallam mendakwakan tauhid selama sepuluh tahun di Mekah. Setelah itu dia diangkat kelangit ketujuh dan diwajibkan kepadanya shalat lima waktu. Kemudian dia shalat di mekah selama tiga tahun. Setelah itu Allah Subhanahu Wa Ta'ala memerintahkannya untuk hijrah ke Madinah. ${ }^{35}$

Ungkapan di atas merupakan sepenggal kisah dari perjalanan Nabi Shallallahu 'Alaihi Wasallam ketika mendakwahkan tauhid di Mekah. Ungkapan di atas juga mengisyaratkan tentang peristiwa besar dalam sejarah Islam, yaitu peristiwa Isra' dan Mi'raj.

d. Metode Motivasi dan Ancaman (Tarhib Wa Targhib)

34 Departemen Agama RI, op. cit., hlm. 17

${ }^{35}$ Abdul Muhsin bin Muhammad Al-Qasimi, op. cit., hlm. 67 
Muhammad bin 'Abdul Wahhab berkata: Sesungguhnya Allah Subhanahu Wa Ta'ala menciptakan dan memberikan rizki kepada kita. Kemudian Allah Subhanahu Wa Ta'ala tidak membiarkan kita begitu saja tanpa adanya perintah, akan tetapi Allah Subhanahu Wa Ta'ala mengutus seorang Rasul kepada kita. Barang siapa taat kepadanya maka ia akan masuk Surga, akan tetapi jika bermaksiat maka akan masuk neraka. Sebagaimana firman Allah Subhanahu Wa Ta'ala yang artinya: "Sesungguhnya Kami telah mengutus kepada kamu (hai orang kafir Mekah) seorang Rasul, yang menjadi saksi terhadapmu, sebagaimana Kami telah mengutus (dahulu) seorang Rasul kepada Fir'aun.Maka Fir'aun mendurhakai Rasul itu, lalu Kami siksa dia dengan siksaan yang berat.( QS. Al-Muzammil: 15-16) 36 $^{36}$

Pernyataan di atas menunjukkan bahwa Muhammad bin 'Abdul Wahhab menerapkan metode tarhib wa targhib dalam melaksanakan pendidikan tauhid, yakni dengan memberikan motivasi kepada pembaca untuk semangat dalam meraih Surga dan membuat pembaca merasa takut terhadap siksa Neraka. Metode ini juga terdapat dalam AlQuran, di antaranya firman Allah Subhanahu Wa Ta'ala:

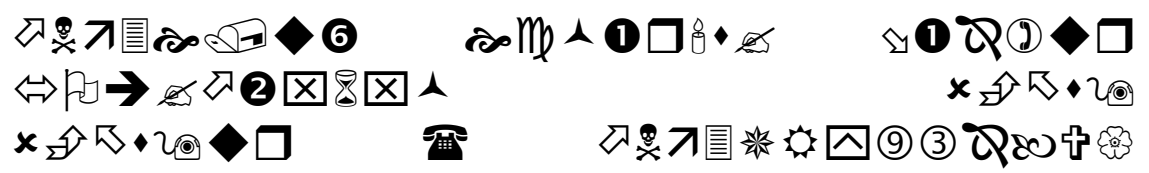

${ }^{36}$ Abdul Muhsin bin Muhammad Al-Qasimi, op. cit., hlm. 45 


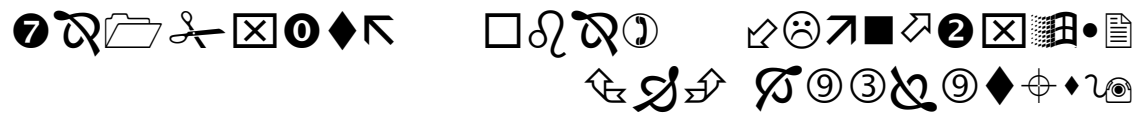
Artinya:

Dan (ingatlah) ketika Tuhanmu memaklumkan; "Sesungguhnya jika kamu bersyukur, niscaya aku akan menambah (nikmat) kepadamu, tetapi jika kamu mengingkari (nikmat-Ku), Maka pasti azab-Ku sangat berat". (QS. Ibrahim: 7$)^{37}$

\section{E. Kesimpulan}

Konsep pendidikan tauhid menurut Muhammad bin 'Abdul Wahhab mengandung lima kesimpulan, yaitu: dasar pendidikan tauhid Al- Quran dan hadits-hadits Nabi, materi pendidikan tauhid meliputi rububiyah, uluhiyah, asma wa sifat, dan tujuan pendidikan tauhid adalah untuk membimbing umat agar mengenal Allah Subhanahu Wa Ta'ala, memurnikan tauhid yang telah tercemar, melepaskan umat dari keterikatan terhadap thaghut, dan mencegah umat agar tidak terjerumus ke dalam kesyirikan.

\footnotetext{
37 Departemen Agama RI, op. cit., hlm. 257
} 


\section{DAFTAR PUSTAKA}

'Abdul 'Aziz Nashir Al-Jalil. 1436 H. Mukhtashar Kitab Wa Lillahi Asmaulhusna. Riyad: Maktabah Al-Mulk Fahd Al-Wathaniyah Atsna An-Nasyr.

Abdul Muhsin bin Muhammad Al-Qasimi. 1435 H. Mutun Thalibil 'Ilmi mustawa awwal. Riyad: Maktabah Al-Mulk Fahd AlWathaniyah Atsna An-Nassyr.

Abdullah bin 'Adul 'Aziz Al-Jibrin. 2002. Tahdzib Tashil Al-Akidah AlIslamiyyah. Riyad: Maktabah Makkah.

Abdullah Zaen. 2010. Ritual-ritual Persembahan di Sekitar Kita. Surakarta: Yayasan Lajnah Istiqomqh Surakarta.

'Abdul Malik bin Ahmad bin Al-Mubarok Ramadhani Al-Hazairi. 2007. Sittu Duror Min Ushuli Ahli Atsar. Kairo: Darul Imam Ahmad.

'Abdul Mun'im Ibrahim. 2000. Mugnil Murid. Riyad: Nizaru Mushtofa Al-Baz.

Abdul Qodir bin Muhammad 'Ath-Thashufi. 2002. AL-Mufid Fi Muhimmati At-Tauhid. Palestina: Darul A'lam.

'Abdurrohman bin Nashir As-Sa'di. 1431 H. Al-Qowa'idul Hisan AlMuta'allaqah Bi Tafsir Al-Quran. Saudi Arabia:Al-Mamlakah Al'Arobiyyah As-Su'udiyyah.

Abu Isa Abdullah bin Salam. 2009. Mutiara Faedah Kitab Tauhid. Yogyakarta: Pustaka Muslim.

Ahmad Madkur. 2001. Manahij At-tarbiyah. Kairo: Darul Fikri Al'Arobiy.

Ahmad Warson Munawir. 1997. Kamus Al-Munawir. Surabaya: Pustaka Progresf. 
Ayu Permata Sari. 2016. Konsep Pendidikan Tauhid Bagi Anak Dalam Buku Segenggam Iman Anak Kita Karya Mohammad Fauzil Adhim (skripsi). Salatiga: IAIN.

Bakar bin 'Abdillah Abu Zaid. 1410 H. At-Tahdzir Min Mukhtasharat Muhammad 'Ali As-Shabuni Fi Tafsir. Riyad: Darul Ibnul Jauzi.

Kementrian Pendidikan dan Kebudayaan. 2017. Pendidikan Agama Islam dan Budi Pekerti. Indonesia: Pusat Kurikulum dan Perbukuan.

Mahmud Ath-Thahhan. 1996. Taisirul Musthalahil Hadits. Riyad: Maktabah Al-Ma'arif.

Muhammad bin Shalih Al-`Utsaimin. 1434 H. Syarah Ushul Fi Tafsir. Riyad: Muassasah Asy-Syaikh Muhammad bin Shalih Al‘Utsaimin. . 1438 H. Al-Qoulul Mufidh 'Ala Kitab At-Tauhid. Riyad: Darul Ibnu Jauzi. . 2000. Syarah Tsalatsatul Ushul. Riyad: Daru Ats-Tsariyya.

Mahmud Syukri Al-Alusi. 2007. Tarikh Najd. Bagdad: Darul Warraq.

Nasrudin Razak. 1989. Dienul Islam. Bandung: Alma'arif.

Nurlaelah Abbas. 2015. Muhammad bin 'Abdul Wahhab: Gerakan Revivalisme dan Pengaruhnya. Jurnal Dakwah Tablig. UIN Alauddin Makasar. Volume 16, nomor 2.

Rasyid Alwani. 2016. Konsep Pendidikan Tauhid Dalam Buku Almatsnawi An-nuri: Menyibak Misteri Keesaan Ilahi Karya Badiuzzaman Said Nursi dan RelevansinyaTerhadap Pendidikan Islam (skripsi). Yogyakarta: UIN Sunan Kalijaga.

Shalih bin Fauzan bin 'Abdullah Al-Fauzan. 2001. Mulakhas Fii Syarhi Kitab At-Tauhid. Riyad: Daarul 'Ashimah. . 2015. Al-Irsyad Ila Shohihi Al-I'tiqod. Riyad: Darul ma'tsur. 
. 1434 H. Akidah At-Tauhid. Riyad: Darul Minhaj.

. 2008. I'anatul Mustafid Bi Syarhi Kitab At-Tauhid. Riyad: Darul 'Ashimah.

. 2017. Syarhu Al-Qowa'id Al-Arba'. Mesir: Daru Sabilu ArRassyad. 2015. Silsilah Syarh Ar-Rasail. Mesir: Darul Ma'tsur

Shalih bin 'Abdul Aziz Alu Syaikh. 1436 H. At-Tamhid. Riyad: Darul Minhaj.

Siti Sukrilah. 2015. Konsep Pendidikan Tauhid Dalam Keluarga Studi Analisis Quran Surat Al-baqarah Ayat 132-133 Dalam Tafsir Ibnu Katsir (skripsi). Salatiga: IAIN.

Teguh Wiyanto. 2014. Pengantar Pendidikan. jakarta: Bumi Aksara.

Tim Penyusun Kamus Pusat Bahasa. 2008. Kamus Bahasa Indonesia. Jakarta: Pusat Bahasa.

Tim Penyusun Pedoman Penulisan Skripsi Program Sarjana (strata-1) STAIM Masjid Syuhada. 2018. Pedoman Penulisan Skripsi. Yogyakarta: STAIMS Press.

Yazid bin 'Abdul Qadir Jawaz. 2015. Kupas Tuntas Memahami Kalimat Syahadat. Bogor: Media Tarbiyah. 